\title{
PENGEMBANGAN BUKU AJAR MATERI PEMBUATAN POLA BERBASIS CAD PATTERN SYSTEM 2 DIMENSI
}

\author{
Luky Triana, Atiqoh, Djoko Adi Walujo \\ Jurusan Teknologi Pendidikan, Sekolah Pascasarjana, Universitas PGRI Adi Buana Surabaya \\ Jl. Dukuh Menanggal XII No. 4, Kec. Gayungan, Kota SBY, Jawa Timur 60234 \\ luky.77.triana@gmail.com
}

Article History

Received: 28 Juli 2021, Accepted: O6 November 2021, Published: 20 November 2021

\begin{abstract}
Abstrak
Tujuan dari penelitian ini adalah menghasilkan produk berupa Buku Ajar Materi Pembuatan Pola Berbasis CAD Pattern System 2 Dimensi, model pengembangan yang digunakan adalah Dick and Carey yang terdiri dari sepuluh tahapan untuk siswa kelas X SMK jurusan Tata Busana. Penggunaan buku ini efektif, hasil belajar dapat ditingkatkan dan interaksi aktif belajar pengguna berbasis CAD Pattern System 2 dimensi yang diberikan dan visualisasi kontekstual serta fitur yang ditawarkan. Dalam memanfaatkan buku CAD Pattern System 2 Dimensi ini, disarankan untuk digunakan secara teratur dan kontinyu mempelajarinya dan mengikuti instruksi yang diberikan. Hasil dari penelitian ini berupa Buku Ajar dengan Materi Pembuatan Pola Berbasis CAD Pattern System 2 Dimensi, penelitian ini memiliki tingkat kelayakan materi 97,5\%, kelayakan desain pembelajaran 96,25\% dan kelayakan media pembelajaran 95\%. Pada prosentase kelayakannya uji coba perorangan sebesar 99,16\%, kelayakan uji coba kelompok kecil adalah 96,67\% dan kelayakan uji coba lapangan 94,71\% dengan kualifikasi sangat layak dan tidak perlu direvisi.
\end{abstract}

Keyword: buku ajar; pola blus; $C A D$

\begin{abstract}
The purpose of this research is to produce a product in the form of a Textbook of Pattern Making Materials Based on a 2-Dimensional CAD Pattern System, the development model used is Dick and Carey which consists of ten stages for class X SMK students majoring in Clothing. The use of this book is effective, learning outcomes can be improved and active user learning interactions based on a 2-dimensional CAD Pattern System are provided and contextual visualization and features offered. In utilizing this 2 Dimensional CAD Pattern System book, it is recommended to use it regularly and continuously study it and follow the instructions given. The results of this study are in the form of Textbooks with Pattern Making Materials Based on 2-Dimensional CAD Pattern System $s$, this study has a material feasibility level of $97.5 \%$, learning design feasibility $96.25 \%$ and learning media feasibility $95 \%$. At the percentage of the feasibility of individual trials of $99.16 \%$, the feasibility of small group trials is $96.67 \%$ and the feasibility of field trials is $94.71 \%$ with very feasible qualifications and does not need to be revised.
\end{abstract}

Keyword: textbooks; Pattern ; CAD 


\section{PENDAHULUAN}

Perkembangan Ilmu Pengetahuan dan Teknologi (IPTEK) berkembang pesat membawa pembaharuan pada pendidikan. Pendidikan merupakan wahana untuk meningkatkan dan mengembangkan kualitas sumber daya manusia, sehingga kelangsungan hidup suatu bangsa dan Negara dijamin atas pendidikan yang baik. Negara berkembang menerapkan pendidikan dengan dua cara, yaitu pendidikan umum (general education) dan pendidikan kejuruan (vocational education) (Disas, 2018; Saleh, Jufari, \& Nasrullah, 2021; Tsani, Ermas, \& Febriantono, 2018).

Pendidikan untuk peserta didik dipersiapkan agar dapat bekerja dalam bidang tertentu merupakan deninisi Pendidikan Sekolah Menengah Kejuruan (SMK) yang sesuai dengan Undang-Undang Nomor 20 Tahun 2003 tentang Sistem Pendidikan Nasional (SISDIKNAS). Dalam pelajaran ini digunakan teknologi komputer yang menerapkan software dalam pembelajarannya. Software (aplikasi) dalam mengajar pola busana secara digital dengan sistem grading salah satunya adalah Software CAD (Computer Aided Design) System dari Richpeace (Ha et al., 2019; Kazantzi et al., 2009; Surani, Hamid, \& Ampera, 2021). Pembuatan pola dengan menggunakan sistem ini lebih produktif dengan membandingkan metode manual bahkan pada model yang sederhana, sehingga sistem pola CAD System akan memberikan keuntungan besar dalam merespon pesanan secara cepat baik dalam berbagai ukuran. Pembuatan pola dengan sistem tersebut dapat memberikan penghematan yang subtansial pada penggunaan kain hingga mengurangi biaya produksi (Cheng, Kuzmichev, \& Adolphe, 2017; Cybenko, Bhasin, \& Cohen, 1997; Siqueira et al., 2016).

Siswa diharapkan dapat menguasai Software CAD (Computer Aided Design) Pattern System dalam Pattern making (pembuatan pola busana), begitu juga pendidik/guru (Hadijah et al., 2018b, 2018a; Sukarno, Sugita, \& Syaefudin, 2014). Pendidik (guru) dan siswa sudah memiliki kemampuan pembuatan pola busana secara manual, namun pembuatan pola secara komputerisasi masih kurang dimiliki. Hal tersebut dibuktikan dengan adanya beberapa pelatihan pembuatan pola secara komputerisasi kepada guru-guru SMK tata busana di beberapa kota (Janah, 2020; Kusumowardhani, 2017; Nurhijrah \& Natsir, 2020). Pelatihan pembuatan pola ini , hanya di beberapa kota, padahal dengan teknologi CAD mereka dapat menghasilkan produk lebih cepat, di samping itu pola busana lebih akurat dan persentase penggunaan bahan lebih efisien dengan Teknik grading dan marking otomatis (Hadijah et al., 2018a; McCartney, Hinds, Seow, \& Gong, 2000; Nurhijrah \& Natsir, 2020; Sukarno et al., 2014).

Pembuatan pola pada dengan teknik digital hakikatnya mampu dilakukan seorang siswa SMK jurusan Tata Busana, pembuatan gambar pola tidak hanya secara manual menggunakan pensil dan kertas. Dengan sistem kerja global dengan pemanfaatan teknologi TIK (Teknologi Informasi dan Komunikasi) siswa tidak tertinggal dan pelajaran yamg dilaksanakan pada pekajaran sekolah sesuai kebutuhan dunia usaha/dunia industri (DUDI). Berdasarkan observasi awal dan hasil wawancara dengan guru SMK (SR) jurusan Tata Busana di Kabupaten Sidoarjo, siswa yang kurang memiliki kompetensi pembuatan pola secara digital (komputer) dengan sistem grading menggunakan aplikasi CAD System masih banyak (Cheng et al., 2017; Hosseini, Soltanian-Zadeh, \& Akhlaghpoor, 2013; Istook, 2000; Mustafa Che Omar \& Siti Fatimah Salleh, 2018). Siswa hanya menguasai ketrampilan tersebut dengan teknik manual sehingga dalam pembuataan pola masih menggunakan waktu cukup lama dalam pembuatan kompenen pola dan membuat prototype. Berdasarkan tinjauan ini, maka siswa perlu mendapatkan pelajaran pembuatan pola busana secara digital melalui pelajaran pembuatan pola busana menggunakan CAD Pattern System 2 Dimensi.

Untuk mencapai kesesuaian materi ajar dengan tujuan pengajaran dalam pembelajaran dan menyediakan fasilitas sehingga diharapkan siswa belajar secara maksimum pemilihan buku sebagai sumber belajar. Dalam membuat sebuah buku diperlukan persyaratan persyaratan antara lain, ketersediaan yang dijangkau oleh siswa, dapat membantu mereka untuk belajar sera dapat memenuhi kebutuhan para siswa dalam belajar mandiri. Hal menarik seperti gambar, ilustrasi, contoh soal (kasus), 
memiliki materi yang mencukupi dapat dipergunakan untuk mendukung kegiatan pemecahan masalah harus dapat diciptakan dalam buku ajar untuk memberikan motivasi . Dalam pengembangan wawasan, buku berguna terhadap proses pembelajaran, sehinnga dapat memberi panduan sebagai langkah-langkah operasional agar dapat menelusuri secara teliti materi standar dan tuntas.

\section{METODE}

Penelitian pengembangan ini menghasilkan produk yang digunakan dalam pembelajaran. Pengembangkan ini berupa buku ajar Pembuatan Pola Berbasis CAD Pattern System 2 Dimensi untuk SMK Jurusan Tata Busana Kelas X semester 2 Model Dick \& Carey. Hasil dari pengembangan buku ajar ini selanjutnya di ujicobakan. (Gunada, I Wayan. Harjono, 2018; Km, Indah, Agung, \& Suartama, 2016; Muga, Suryono, \& Januarisca, 2017; Muntari, 2016) merupakan salah satu model desain pembelajaran yang sistematik.

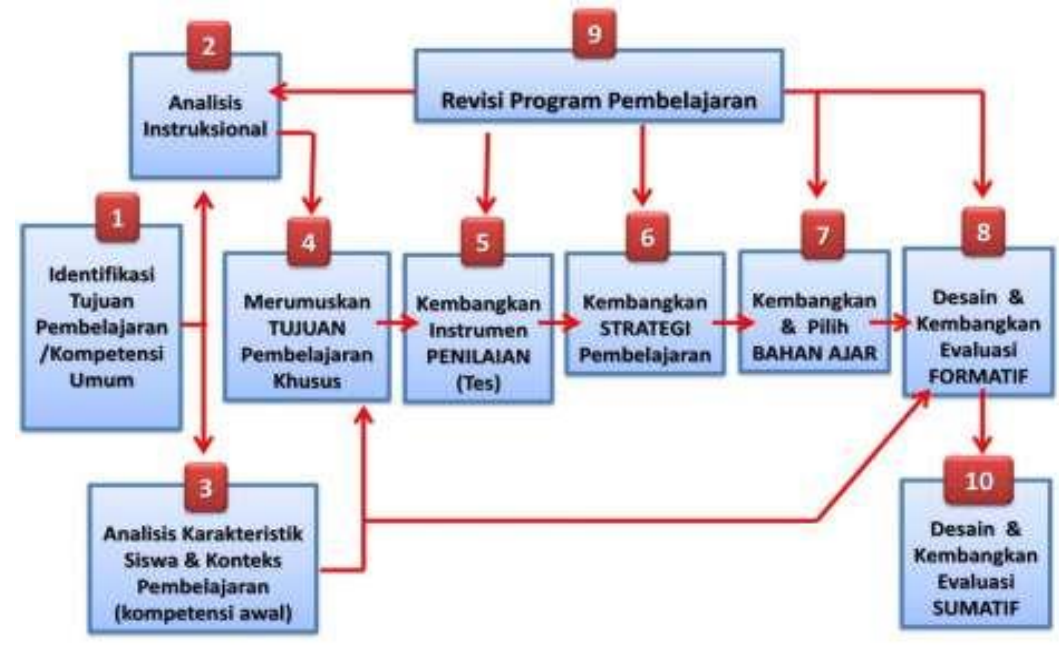

Gambar 1 Model Pembelajaran Dick and Carey (2008)

Prosedur pengembangan pembuatan produk penelitian seperti pada gambar 1 , melalui beberapa tahapan berikut ini :

Mengidentifikasi tujuan pembelajaran terhadap mata pelajaran, tahap ini adalah mengidentifikasikan tujuan umum pembelajaran yang dikembangkan, yaitu apa yang dilakukan siswa setelah mengikuti pelajaran.

Menganalisa pembelajaran, Perumuskan tujuan umum pembelajaran yang dilakukan terlebih dahulu adalah mengidentifikasi Kompetensi inti dan Kompetensi Dasar pada kurikulum 2013 untuk menetapkan pokok bahasan sesuai KI/KD tersebut, kemudian diberikan batasan pada penyusunan tujuan dari pembelajaran yang dijabarkan. Kemampuan apa saja yang sebaiknya dikuasai oleh siswa. Pnyusunan pernyataan tujuan umum menggunakan kata-kata kerja operasional kata-kata kerja operasional.

Mengidentifikasi perilaku awal dan karakteristik siswa, Karakter siswa dientifikasi melalui observasi dan wawancara yang dilakukan pengembang dalam mempertimbangkan dan merancang jenis paket pembelajaran. Penggunaan buku ajar, karakteristik siswa dengan usia rata-rata 16 sampai 17 tahun dapat berfikir secara kongkrit, lancar dalam membaca, siswa menyenangi penggunaan gambar-gambar di buku ajar, gaya belajar secara mandiri dan kelompok.

Menulis tujuan pembelajaran khusus, Sesuai dengan analisis pembelajaran dan masukan tentang karakteristik siswa, selanjutnya guru menyusun pernyataan spesifik dalam menyelesaikan pembelajaran. Penjabaran dari ketrampilan yang dikenali dengan cara menganalisis pembelajaran dengan menyebutkan ketrampilan yang dipelajari. 
Mengembangkan instrumen penilaian, instrumen penilaian merupakan komponen alat ukur, seberapa jauh tingkat keberhasilan siswa untuk pencapaian tujuan pembelajaran khusus. Prestasi siswa merupakan petunjuk untuk tingkat keberhasilan dari pembelajaran sesuai dengan System yang digunakan.

Mengembangkan strategi pembelajaran, ditahap ini, strategi pembelajaran dipilih sesuai dengan tujuan pembelajaran. Strategi yang dipilih berbentuk demonstrasi yang melibatkan partisipasi aktif siswa. Pendekatan pembelajaran kontekstual dikembangkan dalam buku ajar yang dikembangkan menggunakan model Dick and Carey sehingga keaktifan pembelajaran siswa sangat dikedepankan.

Mengembangkan dan memilih materi pembelajaran, Melakukan pengembangan materi didasari pengembangan tujuan umum dan tujuan khusus pembelajaran disesuaikan dengan kurikulum yang berlaku.

Mendesain, melakukan evaluasi formatif, Dalam pertimbangan dalam merevisi paket pembelajaran maka perlu dilakukan kegiatan ini. Tapap Dick and Carey terbagi dalam tiga fase, yaitu evaluasi perorangan (one-to-one), Evaluasi kelompok kecil (small group) dan uji coba lapangan (fiels evaluation)

Merevisi produk pembelajaran, data hasil evaluasi formatif dirangkum dan diinterprestasikan untuk diidentifikasi kesulitan yang dialami oleh pembelajar untuk keberhasilan pembelajaran serta mengatasi kesulitan dengan kekurangan tertentu.

Mendesain dan melaksanakan evaluasi sumatif, efektivitas produk pengembangan perlu diketahui dan diamati. Dengan evaluasi sumatif akan diketahui apakah produk tersebut layak dipakai adan apakah perlu dilakukan evaluasi sumatif.

Data dikumpulkan dengan uji validitas dan efektivitas produk tersebut. Dengan tahapan sebagai berikut: (1) Uji validasi ahli materi dan Media, (2) Uji coba perorangan, dilakukan untuk menemukan kekurangan dan meminimalisir kesalahan, lebih khusus dalam hal redaksional dan teknis penggunaan, (3) Uji coba kelompok kecil ini untuk menguji kekurangan buku ajar dengan pengguna yang lebih besar secara kuantitas setelah direvisi, (4) Uji coba lapangan. untuk memperoleh tanggapan dari komunitas, serta mengidentifikasi permasalahan yang ditemukan dalam penggunaan buku ajar tersebut.

\section{HASIL}

Pengembangan ini menghasilkan produk buku pembuatan pola untuk siswa SMK kelas X Jurusan Tata Busana. Buku ajar ini berdasarkan kurikulum 2013, dan disesuaikan spektrum pedoman penyususnan tujuan pembelajaran . Dilengkapi pula dengan gambar cara pembuatan pola menggunakan aplikasi CAD Pattern System 2 Dimensi.

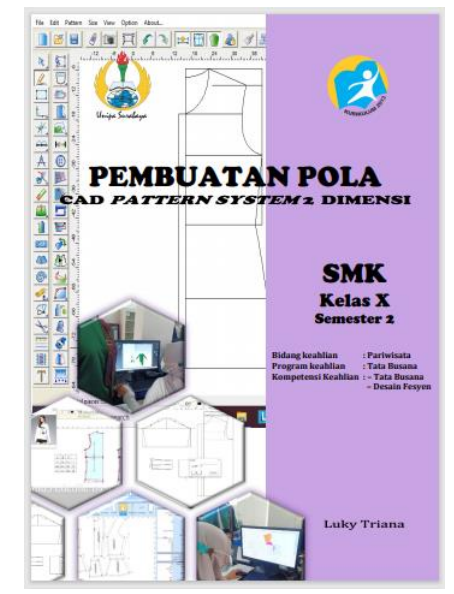

Gambar 2. Halaman sampul buku 
Halaman sampul depan buku ajar berisi tentang judul buku, bidang studi dan kelas yang dijelaskan sesuai gambar 2. Halaman buku dibuat dengan warna sampul buku yang tidak terlalu mencolok dan berisi gambar teknik pembuatan pola CAD Pattern System 2 Dimensi. Sedangkan halaman belakang berisi tentang rangkuman isi dari buku.

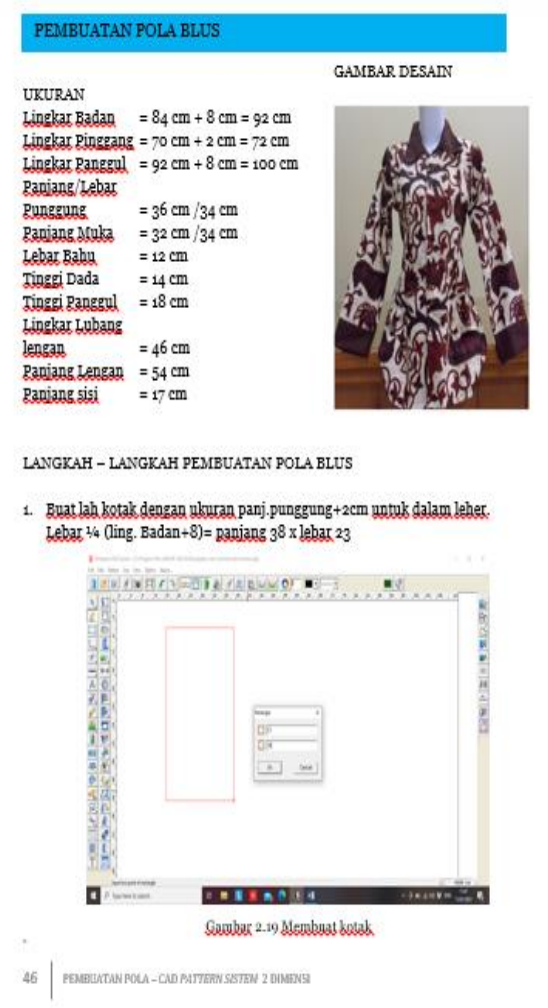

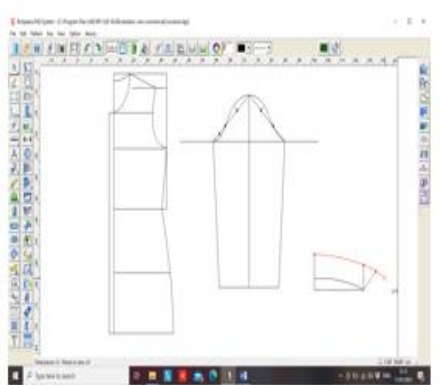

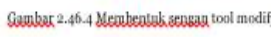

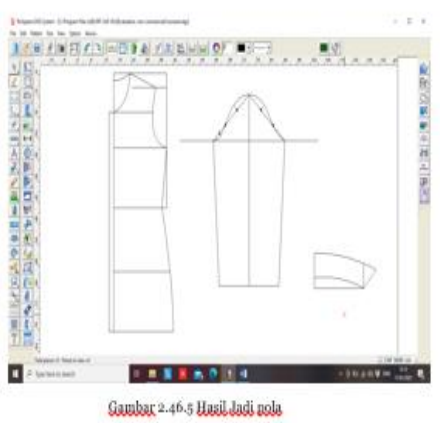

\section{Gambar 3. Contoh isi buku halaman 46 tentang pembuatan pola CAD Pattern System 2 Dimensi}

Gambar 3, merupakan cuplikan gambar dari isi buku. Keunggulan dari materi pada buku ini adalah membuat pola dengan sistem CAD Pattern System 2 Dimensi dengan media computer sebagai media utama dalam pembuatan pola. Dijelaskan juga cara pembuatan pola yang memanfaatkan tools yang pada ribbon, sehingga siswa mencontoh dengan mengikuti petunjuk atau langkah kerja yang ada pada buku.

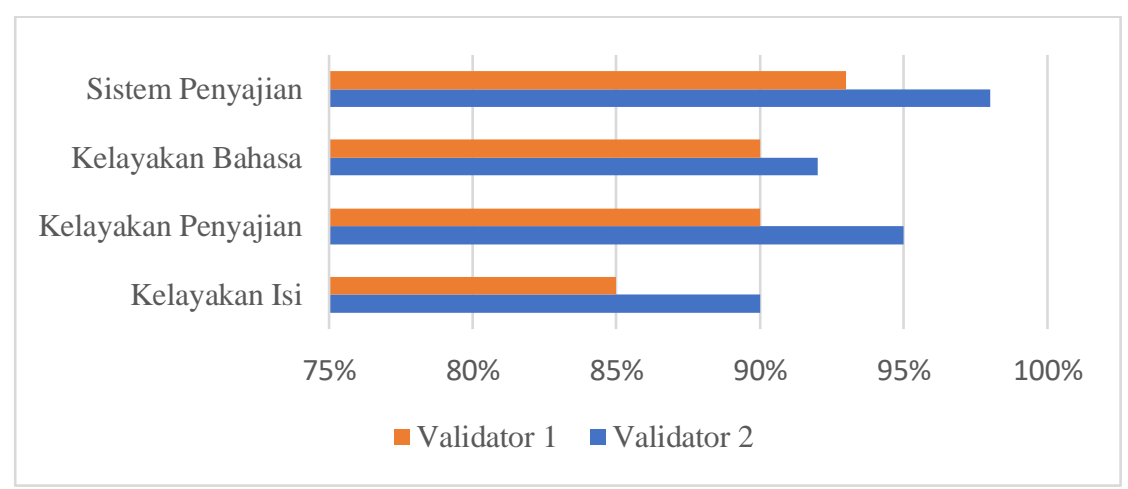

Grafik 1. Presentase penilaian Validasi Ahli Materi/Isi

Buku ajar ini dilakukan uji kelayakan oleh ahli materi, ahli media pembelajaran dan ahli desain pembelajaran. Setelah melakukan revisi sesuai masukan dari para ahli, maka dilakukan uji coba perorangan, uji coba kelompok kecil dan uji coba lapangan yang juga dilakukan revisi pada setiap tahapan uji coba. Data yang dikumpulkan dari uji kelayakan tersebut diolah dan dibandingkan grafik menggunakan persentase mengambil keputusan untuk melihat kualifikasi kelayakan. 
Hasil analisis validasi ahli materi/isi pada grafik 1 menunjukkan buku ajar memperoleh persentase tingkat kelayakan $87,5 \%$. Dari prosentase menunjukkan bahwa produk pengembanagan teraebut baik untuk digunakan sebagai alternatif sumber belajar dan tidak perlu direvisi.

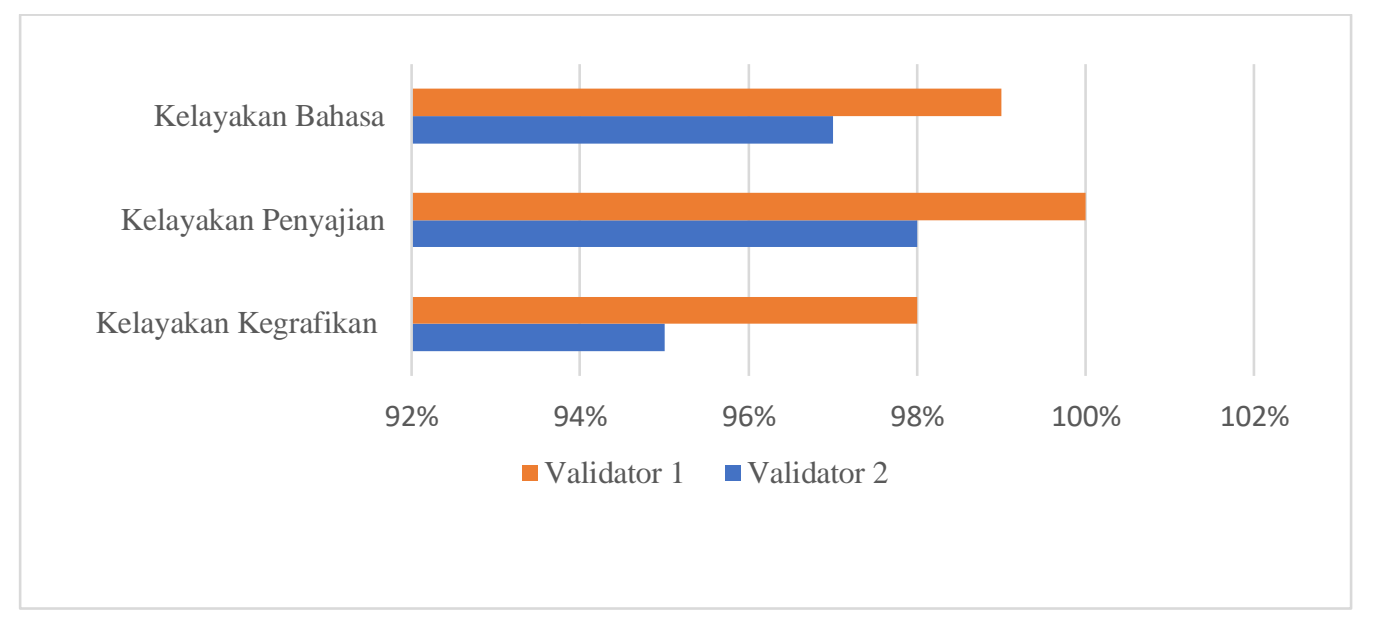

Grafik 2. Presentase Penilaian Validasi Ahli Media

Hasil analisis validasi ahli media pada grafik 2 menunjukkan tingkat kelayakan produk adalah $95 \%$. Dari prosentase tersebut menunjukkan bahwa pengembangan produk sangat layak untuk digunakan sebagai alternatif sumber belajar dan tidak perlu direvisi.

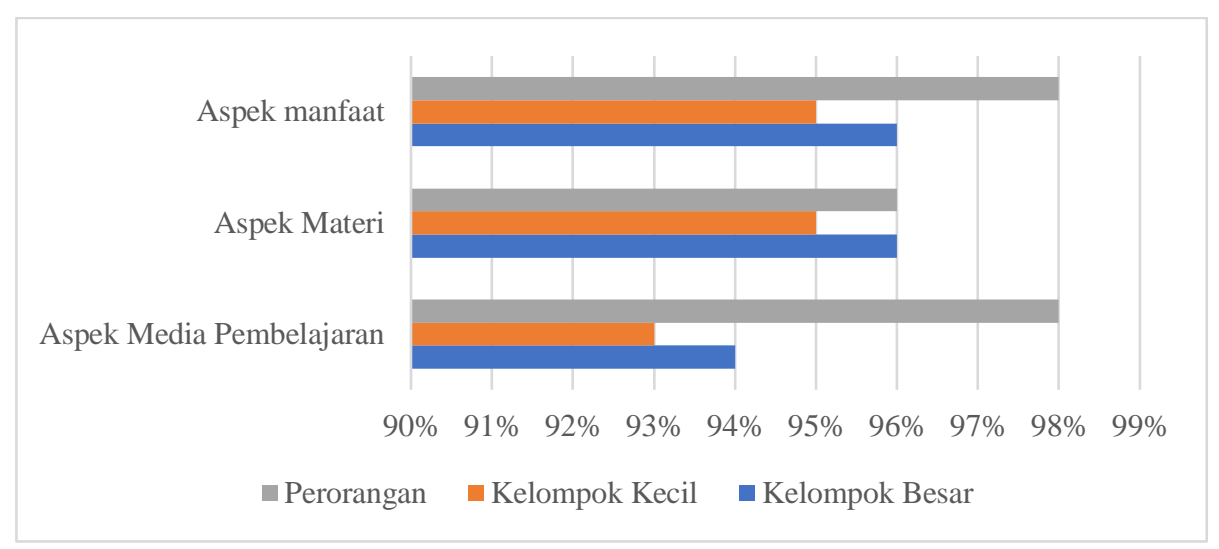

Grafik 3. Presentase Uji Coba kelompok

Berdasarkan grafik 3 hasil uji coba kelompok kecil memperoleh persentase sebesar 96,67\%, yang menjelaskan buku tersebut layak digunakan sebagai alternatif sumber pembelajaran dan tidak perlu direvisi. Namun, komentar dan saran menjadi bahan pertimbangan untuk revisi perbaikan.

\section{PEMBAHASAN}

Dasar penyussnan buku ajar ini adalah sesuai ketentuan atau syarat pembuatan materi ajar yang disesuaiakan dengan materi mata pelajaran, dilengkapi dengan media, selanjutnya menganalisis silabus dan RPP. Media murupakan komunikasi dan sumber informasi dari seseorang yang memberikan informasi kepada penerima informasi. Pembuatan media pembelajaran bertujuan untuk memfasilitasi komunikasi dalam pembelajaran (Sharon; 2018). Model pengembangan buku ajar ini adalah Model pengembangan Dick \& Carey (Gunada, I Wayan. Harjono, 2018; Km, Indah, Agung, \& Suartama, 2016; Muga, Suryono, \& Januarisca, 2017; Muntari, 2016).

Penulisan buku ajar mengikuti pedoman penulisan buku ajar (BPSDMP-PMP, 2012). Dengan memperhatikan kaidah penulisan, yaitu : 1) Tampilan menarik, sehingga meningkatkan minat siswa, 2) Bahasa yang digunakan baku dan mudah di pahami, 3) Komposisi penyusunan buku: judul singkat, tata letak menarik, urutan isi runtut, ada daftar isi dan struktur kognitif jelas, 4) Pemahaman pembaca teruji, sehingga pembaca dapat berkesmpatan untuk mengetahui kemajuan belajar dan berfikir kritis, 
dilengkapi rangkuman dan latihan yang harus dikerjakan, 5) Terbaca, dalam pebilisan digunakan jenis dan ukuran huruf yang standar tidak terlalu kecil atau terlalu besar dan enak dibaca, kalimat dan alinea tersusun dalam struktur yang mudah dipahami, 6) Menggunakan etika dan kaidah penulisan karya ilmiah terpenuhi, tidak diperkenankan untuk menjiplak atau mengambil karangan, pendapat dan sebagainya dari karya orang lain dan menjadikanya seperti hasil pemikiran dan pendapat sendiri (plagiat), karena hal teesebut merupakan tindakan pidana karena telah mencuri hak cipta orang lain. Sumber tulisan yang tercantum dala buku, dikutip dan disesuaikan kaidah penulisan karya ilmiah.

Tahapan uji coba telah dilakukan dalam pengembangan buku ajar ini, sehingga menghasilkan buku ajar Pembuatan Pola Berbasis CAD Pattern System 2 Dimensi. Buku ajar telah dinyatakan layak menjadi bahan belajar dari segi kemenarikan, kegunaan, efektivitas, muatan materi, penataan dari segi desain pembelajaran maupun media yang digunakan. Hadijah et al., (2018b); Kösa \& Karakuş, (2018); Surani et al., (2021) Ciri khas produk ini dapat dijabarkan dalam bagian berikut: Adapun identitas produk pengembangan ini jelaskan sebagai berikut: (1) Nama Program: buku ajar berbasis CAD Pattern System 2 Dimensi; (2) Mata Pelajaran: Pembuatan Pola Blus; (3) Usia Pengguna:14-24 tahun (Remaja awal-remaja akhir).

Media pembelajaran bermanfaat untuk menciptakan pembelajaran menjadi semakin lebih menarik perhatian pebelajar dan menumbuhkan motivasi belajar. Memperjelas isi dari bahan pengajaran , sehingga mudah dipahami oleh pebelajar (Martha, 2018). Media pembelajaran difungsikan untuk : 1) Menarik perhatian siswa, 2) Membantu mempercepat pemahaman pada proses pembelajaran, 3) Penyajian pesan menjadi lebih jelas agar tidak bersifat verbalistis (dalam bentuk kata-kata tertulis atau lisan), 4) Mengatasi pemakaian ruang yang terbatas, 5) Pembelajaran menjadi lebih komunikatif dan produktif, 6) Meengkondiskan waktu pembelajaran dan 7) Siswa dalam belajar tidak mengalami kebosanan (Fathurrohman \& Sutikno, 2009). Secara visual produk ini ini didesain menurut teori-teori yang berlaku seputar teori tentang teks, gambar, penataan visual dan warna sangat penting karena mempengaruhi apakah tujuan atau pesan yang dimaksudkan tercapai atau tidak. Teori tentang warna dijelaskan bahwa permainan warna bukan saja mempengaruhi tampilan semata tetapi juga mempengaruhi kualitas pesan, mempengaruhi emosi dan persepsi karena setiap warna memiliki karakter unik yang berbeda-beda dan sangat mempengaruhi interaksi antara gerakan mata dan proses otak dalam mengelola informasi visual (Khotimah, Supena, \& Hidayat, 2019; Miftah, Rizal, \& Anwar, 2016; Ramadhan, Haeril, \& Medina, 2019).

Warna pada sampul didominasi oleh warna latar putih dan ungu muda, isi background tetap putih dengan template bernuansa hijau dan biru. Jenis dan ukuran huruf dalam buku ini bervariasi, dengan warna huruf seragam yaitu berwarna hitam agar dapat jelas dan kontras dengan latar belakang dominan putih. Teori legibility teks mempengaruhi dari ukuran huruf, tipe huruf dan kontras warna antara latar belakang dan huruf yang sesuai untuk bentuk digital, sekalipun belum ada standar baku untuk teks digital (Camnalbur \& Mutlu, 2011) font, font size, word style (bold, italicized etc). Sesuai banyak penelitian mengusulkan font jenis san serif digunakan dalam teks digital sedangkan san serif font untuk teks cetak (Arifrahara, 2021; Subianto, Anto, \& Akbar, 2018). Penggunaan huruf didominasi oleh jenis san serif seperti Asap 14 point, dan Calibri 16 point.

Karakteristik yang menonjol pada buku ini adanya CAD Pattern System 2 Dimensi. Penelitian lain menyimpulkan bahwa pemberian buku dengan pemilihan materi tersebut dapat memberikan sesuatu yang berbeda, menarik dan layak untuk meningkatkan minat belajar siswa. (Mc Cartney et al., 2000; Xu, Huang, Kang, \& Chen, 2004). Ada banyak metode CAD Pattern System, namun yang diberikan adalah komputer dengan sistem 2 dimensi yakni melalui perangkat komputer/elektronik dengan program tertentu (Hadijah et al., 2018a; Nurhijrah \& Natsir, 2020; Siqueira et al., 2016). Buku ajar Pembuatan Pola Berbasis CAD Pattern System 2 Dimensi dibuat untuk dapat membantu pengguna untuk belajar mandiri. 


\section{SIMPULAN}

Model pengembangan buku ajar ini adalah Dick and Carey. Kesesuaian materi desain dan media yang digunakan, dapat diambil kesimpulan bahwa produk buku ini sangat layak digunakan. Siswa SMK dapat menggunakan buku ini sebagai sumber belajar mandiri. Tanggapan responden-pun positif terhadap pengembangan maupun penggunaan buku. Hal ini menunjukkan bahwa buku layak digunakan sebagai bahan ajar. Penggunaan Buku ini efektif sehingga hasil belajar dapat ditingkatkan dan tercapainya interaksi belajar yang aktif dari pengguna karena memberikan visualisasi kontekstual pada cara dan teknik belajar yang ditawarkan. Dalam memanfaatkan buku ajar ini siswa SMK, disarankan untuk: secara teratur dan kontinyu mempelajarinya dan mengikuti instruksi yang diberikan.

\section{DAFTAR RUJUKAN}

Arifrahara, G. (2021). Analisis Penggunaan Tipografi Spasial Sans Serif Dalam Ruang Publik Taman Tematik Kota Bandung. Andharupa: Jurnal Desain Komunikasi Visual \& Multimedia, 7(01). https://doi.org/10.33633/andharupa.v7i01.3804

Cheng, Z., Kuzmichev, V. E., \& Adolphe, D. C. (2017). Development of knitted materials selection for compression underwear. Autex Research Journal, 17(2). https://doi.org/10.1515/aut-2016-0006

Cybenko, G., Bhasin, A., \& Cohen, K. D. (1997). Pattern Recognition of 3D CAD Objects: Towards An Electronic Yellow Pages of Mechanical Parts. International Journal of Smart Engineering System Design, 1(1).

Dewanti, H., Toenlioe, A. J., Soepriyanto, Y. (2018), Pengembangan Media POP-UP Book Untuk Pembelajaran Lingkungan Tempat Tinggalku Kelas IV SDN 1 Pakunden Kabupaten Ponorogo. Jurnal Kajian Teknologi Pendidikan. 1(3). 221-228.

Disas, E. P. (2018). Link and Match sebagai Kebijakan Pendidikan Kejuruan Link and Match as a Vocational Education Policy. Jurnal Penelitian Pendidikan, 18(2).

Gunada, I Wayan. Harjono, A. G. (2018). Pelatihan Mendesain Penelitian Tindakan Kelas dan Pengembangan Model Dick And Carey Bagi Guru-Guru Di Sma Negeri 1 Narmada. Jurnal Pendidikan Dan Pengabdian Masyarakat, 53(9).

Ha, T., Jung, Y., Kim, J. Y., Park, S. Y., Kang, D. K., \& Kim, T. H. (2019). Comparison of the diagnostic performance of abbreviated MRI and full diagnostic MRI using a computer-aided diagnosis (CAD) System in patients with a personal history of breast cancer: the effect of CAD-generated kinetic features on reader performance. Clinical Radiology, 74(10). https://doi.org/10.1016/j.crad.2019.06.025

Hadijah, I., Kusumawardani, H., Aini, N., Studi, P., Busana, T., Teknik, F., \& Malang, U. N. (2018a). Kompetensi Pembuatan Pola Busana Berbasis CAD Pattern System Guru SMK Tata Busana Di Malang Raya. Jurnal KARINOV, 1(2).

Hadijah, I., Kusumawardani, H., Aini, N., Studi, P., Busana, T., Teknik, F., \& Malang, U. N. (2018b). Pattern System Guru Smk Tata Busana Di Malang. Teknologi Dan Kejuruan, 1(2).

Hosseini, M. P., Soltanian-Zadeh, H., \& Akhlaghpoor, S. (2013). Three Cuts Method For Identification of COPD. Acta Medica Iranica, 51(11).

Istook, C. L. (2000). Rapid prototyping in the Textile \& Apparel industry: A pilot project. Journal of Textile and Apparel, Technology and Management, 1(1).

Kazantzi, A., Korfiatis, P., Skiadopoulos, S., Daoussis, D., Petsas, T., Costaridou, L., \& Kalogeropoulou, C. (2009). Quantification Of Interstitial Lung Disease Extent In Collagen Vascular Disease: Preliminary Results Exploiting A Pattern Based CAD System. Journal of Thoracic Imaging, 24(3).

Khotimah, H., Supena, A., \& Hidayat, N. (2019). Meningkatkan Attensi Belajar Siswa Kelas Awal Melalui Media Visual. Jurnal Pendidikan Anak, 8(1). https://doi.org/10.21831/jpa.v8i1.2265 
Km, I. G. A., Indah, N., Agung, G., \& Suartama, I. K. (2016). Pengembangan Mobile Learning Dengan Model Dick Dan Carey Pada Mata Pelajaran Biologi Di Smpn 5 Mendoyo. E-Journal Edutech Universitas Pendidikan Ganesha, 5(2).

Kösa, T., \& Karakuş, F. (2018). The Effects Of Computer-Aided Design Software On Engineering Students' Spatial Visualisation Skills. European Journal of Engineering Education, 43(2). https://doi.org/10.1080/03043797.2017.1370578

Lestari, R. T, Adi, E. P., Soepriyanto, Y. (2018). E Book Interaktif. JKTP: Jurnal Kajian Teknologi Pendidikan, 1(1), 71-76 . http://journal2.um.ac.id/index.php/jktp/article/view/3529

Martha, Z. D., Adi, E. P., Soepriyanto, Y. (2018). E-book Berbasis Mobile Learning. JKTP: Jurnal Kajian Teknologi Pendidikan 1 (2). 109-114.

McCartney, J., Hinds, B. K., Seow, B. L., \& Gong, D. (2000). Dedicated 3D CAD for Garment Modelling. Journal of Materials Processing Technology, 107(1-3). https://doi.org/10.1016/S0924-0136(00)00695-6

Muga, W., Suryono, B., \& Januarisca, E. L. (2017). Pengembangan Bahan Ajar Elektronik Berbasis Model Problem Based Learning Dengan Menggunakan Model Dick And Carey. Journal of Education Technology, 1(4). https://doi.org/10.23887/jet.v1i4.12863

Muntari, L. (2016). Pengembangan bahan ajar membaca Bahasa Indonesia untuk kelas V SD dengan Model Dick dan Carey. Media Didaktika, 2 (2).

Nurhijrah, N., \& Natsir, N. (2020). Pengembangan Kompetensi Guru dalam Membuat Pola Digital dengan menggunakan CAD System . Journal of Millennial Community, 2 (1). https://doi.org/10.24114/jmic.v2i1.18623

Omar, M. C., \& Salleh, S. F. (2018). Keperluan Terhadap Guru Resos Bagi Program Pendidikan Inklusif Di Sebuah Sekolah Menengah: Satu Kajian Kes. Prosiding Seminar Kebangsaan Majlis Dekan Pendidikan Universiti Awam 2018.

Pratiwi, K. B., Sugito, Subandowo, M., (2018) The Development POP-Up Books To Improve Children's Language Skills. JKTP: Jurnal Kajian Teknologi Pendidikan. 3(4), 408-414. http://journal2.um.ac.id/index.php/jktp/article/view/14645

Ramadhan, A., Haeril, F. K., \& Medina, R. (2019). Kajian Visual Kemasan Sebagai Media Informasi. MAVIS : Jurnal Desain Komunikasi Visual, 1(02). https://doi.org/10.32664/mavis.v1i02.415

Saleh, S., Jufari, J., \& Nasrullah, M. (2021). Analisis Prestasi Belajar Mahasiswa Lulusan Sekolah Menengah Umum Dan Sekolah Menengah Kejuruan. Efisiensi : Kajian Ilmu Administrasi, 18(1). https://doi.org/10.21831/efisiensi.v18i1.35911

Siqueira, F., Cardenas, A. M., Gutierrez, M. F., Malaquias, P., Hass, V., Reis, A., ... Perdigão, J. (2016). Laboratory performance of universal adhesive System s for luting CAD/CAM restorative materials. Journal of Adhesive Dentistry, 18(4). https://doi.org/10.3290/j.jad.a36519

Subianto, I. B., Anto, P., \& Akbar, T. (2018). Perancangan Poster sebagai Media Edukasi Peserta Didik. Jurnal Desain, 5(03). https://doi.org/10.30998/jurnaldesain.v5i03.2425

Sukarno, R., Sugita, I. W., \& Syaefudin, E. A. (2014). Pelatihan Dasar-Dasar CAD/Cam/Cae Dan Software AutoCAD Untuk Guru-Guru Smk Bidang Keahlian Teknik Mesin Di Wilayah Kabupaten Bekasi. Sarwahita, 11(2). https://doi.org/10.21009/sarwahita.112.10

Surani, S., Hamid, A., \& Ampera, D. (2021). Blended Learning Based Optitex Media Development for Students in Fashion Design Education Study Program State University of Medan. Budapest International Research and Critics in Linguistics and Education (BirLE) Journal, 4(1). https://doi.org/10.33258/birle.v4i1.1657

Tsani, T., Ermas, E., \& Febriantono, A. R. (2018). Efisiensi Belanja Pendidikan Sekolah Menengah Kejuruan Dan Pengaruhnya Terhadap Pemenuhan Akses Pendidikan Menengah Di Indonesia. Jurnal Anggaran Dan Keuangan Negara Indonesia (AKURASI), 2(1). https://doi.org/10.33827/akurasi2018.vol2.iss1.art36 
Xu, Y., Huang, T., Kang, J., \& Chen, Y. (2004). Development of a 3-D CAD software System in expendable Pattern casting. Tezhong Zhuzao Ji Youse Hejin/Special Casting and Nonferrous Alloys, (4). 